\title{
A DEPOSIÇÃO DE LUGO E OS LIMITES DA DEMOCRACIA NA AMÉRICA LATINA
}

\author{
THE DEPOSITION OF PRESIDENT LUGO AND THE LIMITS \\ OF DEMOCRACY IN LATIN AMERICA
}

\section{Fabio Luis Barbosa dos Santos ${ }^{(*)}$}

\begin{abstract}
Resumo: Analisamos neste texto as circunstâncias da deposição do presidente paraguaio Fernando Lugo consumada em junho de 2012, relacionando as motivações imediatistas que desencadearam o golpe às tensões que caracterizam a questão agrária no Paraguai, bem como aos limites da transição democrática operada no país desde o final da ditadura comandada por Alfredo Stroessner em 1989.
\end{abstract}

Palavras-chave: Fernando Lugo; Paraguai; Golpe; Democracia.

\begin{abstract}
This article analyses the circumstances in which Paraguayan president Fernando Lugo was deposed in June 2012, relating the immediate motivations that triggered the coup to the tensions that characterize the land issue in Paraguay, as well as to the limits of the democratic transition that has followed the end of the dictatorship led by Alfredo Stroessner in 1989.
\end{abstract}

Keywords: Fernando Lugo; Paraguay; Coup; Democracy.

(*) Doutor em História Econômica. Professor da UNILA (Universidade Federal da Integração Latino-Americana). Esta pesquisa integrou o projeto "Estrutura Socioeconômica e Políticas para a Integração da América do Sul" do IPEA (Instituto de Pesquisa Econômica Aplicada). E-mail: < fabiobarbosasantos@gmail.com>. Recebido em 30.10.2012 e aceito em 08.05.2013. 


\section{MARCO GERAL DA ELEIÇÃO DE LUGO}

A eleição de Fernando Lugo como presidente paraguaio em 2008 representou a primeira alternância à dominação colorada na política paraguaia desde a ascensão de Alfredo Stroessner ao poder em 1954. A ditadura comandada pelo general chegou a termo em 1989 por meio de um golpe militar liderado por um subordinado seu, o general Andrés Rodríguez. Eventos dramáticos que animaram a política nacional nos anos seguintes, como o assassinato do vice-presidente Argaña em 1999 e a subsequente renúncia de Cubas Grau perante a pressão popular (o chamado "marzo paraguayo"), as desventuras que levaram o general Lino Oviedo ao exílio e à prisão (e a dissidência intracolorada que liderou), entre outros, não transbordaram os marcos da dominação colorada. Embora a gestão do Estado após a ditadura envolvesse, em alguma medida, o compartilhamento do aparelho estatal com a oposição conservadora, a transição paraguaia foi operada pelo mesmo partido que sustentou a ditadura, caso singular no continente. Neste contexto os liberais, rivais dos colorados nos marcos da política conservadora desde o final do século XIX, enxergaram na adesão à candidatura Lugo nada mais do que um caminho para reaproximarem-se do Poder Executivo.

Por outro lado, o campo popular identificou nesta novidade política uma oportunidade para avançar demandas há muito represadas. País pouco industrializado, que apresenta o IDH (Índice de Desenvolvimento Humano) mais baixo da América do Sul aliado a uma das maiores concentrações de riqueza do continente, o foco das tensões sociais desde o final da ditadura tem sido a questão agrária. Relata-se que no dia seguinte à deposição de Stroessner registraram-se três ocupações de terra ${ }^{(1)}$.

As tensões no campo paraguaio acentuaram-se a partir dos anos 1990 ante a explosão do cultivo da soja, atividade protagonizada principalmente, embora não exclusivamente, por empresários de origem brasileira associados às transnacionais do agronegócio, conhecidos como "brasiguaios". Estima-se que em 1973 o cultivo de soja ocupava 40 mil hectares no país. Em 1996, a superfície plantada aproximava-se de 1 milhão de hectares. Com a introdução de sementes transgênicas no final do decênio, calcula-se que a fronteira da soja avançou em média 125 mil hectares por ano nas safras seguintes, alcançando 2,8 milhões de hectares no ciclo agrícola de 2010/2011 (PALAU, 2012). Nesse período, o país manteve altas taxas de crescimento, rompendo com a letargia prevalente desde a construção de Itaipu: em 2010, por exemplo, o ritmo da expansão da economia paraguaia só ficou atrás do Catar. Atualmente, é o quarto exportador mundial de soja e o nono de carne bovina. Essa agressiva penetração do agronegócio incidiu na composição da classe dominante no país, cuja anatomia é resumida pelo sociólogo Tomas Palau:

De ese modo, se conformó la estructura del poder real en Paraguay, basada fundamentalmente en cuatro grupos: la oligarquía ganadera, los narcos, los "empresaurios" y las multinacionales. Como quedó dicho, el primero es el más antiguo; el segundo

(1) "En la tarde del 3 de febrero de 1989, los sin tierra con el apoyo de sus organizaciones ocupan dos latifundios improductivos de 10 mil y 11 mil hectáreas en la localidad de Maracaná, distrito de Curuguaty (Canindeyu) y otro de 5 mil hectáreas en Limoy, distrito de Minga Porä (Alto Paraná). Estas ocupaciones, realizadas en el mismo día de la apertura democrática, significaban la emergencia de numerosos casos de conflictos que permanecían ocultos por temor a la represión del régimen depuesto, eran el preludio de las masivas ocupaciones de tierra que vendrían posteriormente y representaban una dura prueba para la nueva administración del gobierno." (RIQUELME, 2003) 
y el tercero se instalaron con Stroessner; el último es el poder emergente a partir del golpe de 1989 y está integrado por quienes pasan a ser los "adalides" de la democracia mínima que rige en el país hoy. (PALAU, 2012, p. 226)

A expansão concomitante da soja e da pecuária em um contexto em que se esgotava a disponibilidade de terras do Estado (as chamadas "tierras fiscales"), acirrou as contradições entre o agronegócio e os modos de vida de orientação camponesa, além de causar devastação ambiental no oriente do país e no Chaco, onde encontra-se ameaçado, por exemplo, um dos últimos grupos aborígenes que vive em isolamento voluntário no continente, os ayoreo. Como uma resposta a este movimento, recrudesceu a resistência organizada de camponeses e indígenas no único país oficialmente bilíngue do cone sul, que se expressou em uma dinâmica de luta pela terra e repressão estatal familiar aos países latino-americanos.

Fernando Lugo, embora não tivesse uma militância reconhecida no campo da esquerda ${ }^{(2)}$, projetou-se como figura política por meio de uma atuação episcopal afinada com a sensibilidade social característica da teologia da libertação, exercida no interior do país neste contexto de aguçamento das tensões no campo. Como candidato, fez da reforma agrária a sua principal promessa de campanha, arrebanhando o apoio daqueles que empatizavam com as mudanças sociais.

Esposada pelos setores populares, mas lastreada na estrutura partidária liberal, a candidatura de Lugo consumou um casamento de conveniência, em que ensejos díspares convergiram sob o desígnio comum de derrotar os colorados. Como decorrência, seu triunfo eleitoral pode ser interpretado antes como uma rejeição à situação prevalente do que como um triunfo da esquerda, em um país em que as forças populares estiveram asfixiadas por meio século de dominação colorada, na maior parte sob ditadura, e encontram dificuldades em solidificar instrumentos de política autônoma. Neste sentido, a eleição de Lugo encontra paralelo em outros casos no continente, em que desconhecidos alçaram-se ao Poder Executivo por meio de arranjos políticos ad hoc, em uma conjuntura de desprestígio dos partidos e dos políticos convencionais, desgastados diante da impopularidade do receituário neoliberal. Questionado sobre as convicções políticas do novo presidente, um futuro integrante do governo resumiu o espírito prevalente: não me perguntem sobre quem entra, mas sim sobre quem sai.

\section{SOBRE O GOVERNO LUGO}

Dentre aqueles que simpatizaram com a vitória de Lugo, há dúvidas em relação à vontade política que o governo demonstrou para transformar a realidade, mas há consenso sobre os obstáculos que enfrentou. Eleito com $40,9 \%$ dos votos em uma aliança com os liberais, que indicaram o vice-presidente, as agremiações no campo da esquerda que integraram a coligação elegeram 3 dentre os 80 deputados, e um igual número de senadores de um total de 45. Para constituir maioria nas câmaras, o Executivo precisaria compor não

(2) Milda Rivarola indica que Lugo não teve uma militância anti-stronista pública e por esse motivo não consta entre as milhares de pessoas fichadas pelo regime como potenciais opositores. A mesma professora aponta que a projeção política de Lugo foi originalmente impulsionada pela agrupação "Patria Querida", de notória extração empresarial. 
somente com os liberais, que elegeram 29 deputados e 14 senadores, mas também com a dissidência colorada comandada por Lino Oviedo sob a sigla UNACE (Unión Nacional de Ciudadanos Éticos). A frágil autonomia do presidente é realçada pela constituição em vigor, oriunda da transição, e que acentua a dependência do Executivo em relação ao parlamento. Nesta circunstância, são evidentes os constrangimentos enfrentados para propor mudanças substantivas por meio dos canais legais vigentes, considerando o perfil dos parlamentares em questão, descrito nestas palavras por um estudioso anglo-saxão:

The most obvious thing to note is that they are almost all large rural landowners, with titles held either directly or in the names of friends and family. In 2008, a former head of the World Bank in Paraguay expressed his shock at discovering that virtually every member of congress that he met fitted this description. Many were also beneficiaries of the illegal transfer of large tracts of state lands (typically 2,000 hectares and above) to military and civilian supporters of the Alfredo Stroessner dictatorship, a process that continued through the subsequent two decades of Colorado governments. (NICKSON, 2012)

Diferente de outros casos recentes no continente, Lugo não cogitou convocar uma Assembleia Constituinte, o que exigiria, de todo modo, uma força política que aparentemente não tinha para comandar o processo - como aconteceu na Venezuela, na Bolívia e no Equador. Em todo caso, não era esta a proposta de Lugo e analistas paraguaios consideram esta aproximação equivocada à luz do que o governo efetivamente se propôs a fazer.

Em um arranjo que lembra o primeiro governo Lula, os ministérios mais importantes foram alocados a personalidades de confiança do capital - como a Fazenda, Obras Públicas e Agricultura y Ganadería -, enquanto abriu-se espaço para o campo popular na Saúde e em organismos menores - como o Ministério da Cultura, a Secretaria de Indígenas, a Secretaria Ambiental e o Indert (Instituto Nacional de Desarrollo Rural y de la Tierra - espécie de INCRA paraguaio). Programas sociais de caráter assistencial foram implementados e abriram-se múltiplos espaços de participação cidadã que, no entanto, não significaram qualquer mudança estrutural.

Em que pese a inocuidade das políticas sociais avançadas, os principais movimentos de trabalhadores rurais adotaram uma espécie de "trégua" em relação ao governo — o que significou uma moderação, mas não a cessação de ocupações e marchas. Entendia-se que a pressão social poderia desestabilizar um mandato que, apesar de suas debilidades, pela primeira vez lhes abria as portas presidenciais. Em certa medida, não era uma leitura equivocada, considerando-se os eventos subsequentes.

A boa vontade expressa pelos movimentos populares em relação ao governo não foi recíproca. Pelo contrário, houve uma aproximação com a Colômbia em assuntos relacionados à segurança nacional comandada pelo Ministério do Interior, que resultou em treinamentos e assessorias diversas referenciadas no famigerado Plan Colombia. Lugo também aprovou uma lei antiterrorista votada pelo parlamento nos moldes difundidos pelos Estados Unidos, além de permitir o estabelecimento da Iniciativa Zona Norte, prevendo a instalação e o exercício de tropas estadunidenses na região oriental do país (MENDEZ, 2012). 
Nesse cenário, a repressão aos movimentos sociais no campo não abrandou, registrando-se dezenas de casos de violência em consonância com o padrão prevalente em governos anteriores, inclusive o assassinatos de militantes. Segundo observadores dos direitos humanos, o momento culminante dessa política de segurança referida ao Plan Colombia ocorreu em meados de 2010, quando o governo declarou estado de sítio em cinco departamentos do país (equivalentes a Estados no Brasil). Sob pretexto de erradicar um movimento que se supõe guerrilheiro denominado EPP (Ejercito del Pueblo Paraguaio), cometeram-se inúmeras infrações aos direitos civis de militantes camponeses. Muitos fazem a leitura de que o EPP, uma obscura organização constituída por um punhado de membros que realiza atos esporádicos de banditismo social, cumpre um papel funcional a um discurso que, modulado na ideologia do combate ao terrorismo, avaliza políticas de policiamento social como ocorre na Colômbia (PALAU, 2009). De todo modo, a oposição a Lugo sistematicamente buscou vincular o presidente ao EPP, o que levanta a suspeita de nexos entre esta organização e a dimensão mafiosa da política nacional.

\section{A QUESTÃo AGRÁRIA NO GOVERNO LUGO}

Foi nesses marcos que se inscreveu a política agrária do governo Lugo. De modo geral, os militantes pela reforma agrária diagnosticaram cedo as ambivalências do governo, criticando uma dispersão de esforços interpretada como falta de vontade política para transcender a retórica:

Puede apreciarse fácilmente que esta gran cantidad de planes, programas, proyectos e iniciativas de diferentes reparticiones gubernamentales, elaborados muchos de ellos de manera paralela (en el mejor de los casos) o de manera antagónica cuando los intereses en pugna eran o son políticamente distintos, no puede sino ofrecer un panorama desolador: es la más clara expresión de que no se hará nada. (RIQUELME, ROJAS, PALAU, 2010, p. 31)

Antes de analisar os conflitos por terra que tiveram maior visibilidade pública durante o governo Lugo e cuja dinâmica evidencia os impasses enfrentados em relação ao tema, é preciso uma aproximação sumária aos termos em que se problematiza a reforma agrária no país.

De acordo com conhecedores da questão agrária, há três maneiras legais para proceder à distribuição de terra no Paraguai: a compra, a expropriação ou a recuperação de terras. Aparentemente menos conflitiva, a compra de terras torna-se impraticável na medida em que a legislação a enquadra como a aquisição de uma propriedade qualquer, que deve ser submetida à licitação pública. Apenas terras imprestáveis ao cultivo ou de remoto acesso são ofertadas. Na prática, a ação do Estado resume-se a comprar terras já ocupadas, em que não há perspectiva de recuperação da posse. A expropriação também é descartada em função dos baixíssimos níveis de produtividade requeridos pelo Estatuto Agrário, além da falta de recursos próprios para o INDERT comprar terras a preço de mercado.

Por fim, existe a possibilidade de recuperar lotes irregularmente adquiridos — conhecidos como tierras mal habidas. A origem destas propriedades espúrias está intimamente vinculada à ditadura de Stroessner e à problemática brasiguaia. Na maior parte dos casos, 
trata-se de terras distribuídas pelo regime a favorecidos seus sob a cobertura do programa de colonização então promovido. O início da imigração brasileira massiva ao país também se dá neste contexto, resultado da convergência entre o interesse do regime stronista em ocupar o território mediante a agricultura mercantil e a expansão da fronteira agrícola brasileira, pressionada por múltiplas variáveis. Atraídos pelo baixo preço relativo das terras, uma pressão fiscal praticamente inexistente ${ }^{(3)}$ e a permissividade do Estado em relação a questões jurídicas e ambientais, alguns dentre os cerca de 400 mil brasileiros ${ }^{(4)}$ que cruzaram a fronteira nas últimas décadas amealharam em torno a $40 \%$ das terras dedicadas à soja no país, principal gênero exportado pelo Paraguai (GLAUSER, 2009).

Ao longo destes anos, os brasileiros envolveram-se nas falcatruas por dois caminhos principais: negociando as terras apropriadas pelos favorecidos do regime, mas também adquirindo lotes distribuídas aos que seriam os genuínos beneficiários da colonização. Estas terras são denominadas derecheras, pois consistem na cessão do direito (derecho) de ocupação de um pedaço de terra concedido pelo Estado e que, portanto, não pode ser vendido. Como um agravante, brasileiros adquiram terras na região fronteiriça, situação que o governo procurou regulamentar por meio de uma lei vigente desde 2005, que cria uma zona de segurança onde é proibida a propriedade de estrangeiros em um raio de 50 quilômetros da divisa internacional. Esta lei foi severamente criticada pelas classes dominantes do país ${ }^{(5)}$.

O primeiro diretor do INDERT no governo Lugo, Alberto Alderete, trabalhara em uma extensiva investigação com o objetivo de mapear as tierras mal habidas, trabalho impulsionado pela Comisión de Verdad y Justicia, cujo intuito era apurar o legado da ditadura stronista em diferentes esferas. O resultado apontou que, de um total de 12.229.594 de hectares de terras distribuídas ao longo da ditadura, $64,1 \%$ foram apropriadas ilegalmente, o que constitui cerca de 1/5 da área do país. Em outras palavras, haveria 7,8 milhões de hectares de terras ilegalmente apropriadas e portanto, passíveis de serem expropriadas pelo governo. Uma lista com 3.336 nomes referidas a 4232 propriedades foi divulgada,

(3) Além de um baixíssimo imposto sobre a terra, a exportação da soja está isenta de tributação. Somente em 2012 há uma primeira tentativa em instituir um imposto sobre rendimentos de pessoa física. A pressão tributária no Paraguai é cerca de 13\% do PIB e 60\% do imposto são arrecadados por meio do IVA (Impuesto al Valor Agregado), que incide sobre o consumo. O imposto imobiliário representa $0,04 \%$ da pressão tributária, embora o agronegócio seja responsável por cerca de 30\% do PIB paraguaio. Ver: MENDEZ, 2012.

(4) Não há estatísticas precisas: "Hay una mayor disparidad de opiniones en cuanto al volumen de la migración brasileña. Esto se refleja en la gran diferencia reportada en los documentos oficiales del Paraguay (censos nacionales de población e informes del Ministerio del Interior) y las cifras de fuentes oficiales y no gubernamentales del Brasil, como también en los estudios realizados por investigadores de ambos países. Así, mientras el Censo de Población y Viviendas (1992) consignaba una población de 108.528 brasileños, y el último Censo (2002), registra una cantidad de 81.616, las estimaciones oficiales de Itamaraty (Ministerio de Relaciones Exteriores del Brasil) hechas en diferentes épocas oscilaban entre 350.000 y 500.000. Voceros de la Pastoral del Migrante de ambos países — quienes fueron entrevistados en julio del 2004 - calcularon en alrededor de 350.000 el número de inmigrantes brasileños en el Paraguay" (FOGEL; RIQUELME, 2005, p. 127-8).

(5) A resistência se evidenciou quando o presidente Fernando Lugo tentou regulamentar a referida lei por meio do Decreto n. 7.525: "El diario ABC señaló: 'El presidente Fernando Lugo creó mediante un decreto obligaciones no establecidas en ley alguna para los propietarios de tierras, con lo cual se atribuyó funciones que son exclusivas de Poder Legislativo. Mediante el decreto que reglamenta la franja fronteriza, pretende aplicar agora presión militar sobre los productores'; por su parte, la Federación de Cooperativas de la Producción (FECOPROD) manifestó también su profonda preocupación ante el reciente Decreto n. 7.525/2011, por el cual 'se reglamenta' la Ley de Zona de Seguridad Fronteriza" (PROGRAMA DEMOCRATIZACIÓN Y CONSTRUCIÓN DE LA PAZ, 2012, p. 8). 
encabeçada pelo próprio Stroessner e por Andrés Rodriguez, o militar que o derrubou. Segundo o sociólogo Ramón Fogel, outro dos responsáveis pela investigação, 90\% das tierras mal habidas estariam em posse de brasiguaios na atualidade (PROGRAMA DEMOCRATIZACIÓN Y CONSTRUCIÓN DE LA PAZ, 2012, p. 27).

Apesar da difusão pública do informe produzido e do notório conhecimento de causa de Alderete, sua breve gestão ante o pequeno e corrompido INDERT (agosto de 2008 a março de 2010) foi incapaz de produzir qualquer resultado significativo, chocando-se com o bloqueio jurídico às recuperações de terra, a sabotagem financeira à instituição e a defenestração política conduzida pela imprensa.

$\mathrm{Na}$ realidade, a crise que provocou sua queda foi desencadeada por um episódio incomparavelmente menor do que a desapropriação de um quinto do território nacional. Em uma tentativa de promover alguma distribuição de terra, o INDERT negociou a compra de 22.000 hectares de um brasileiro, Ulisses Rodriges Teixeira, por cerca de U\$ 30 milhões, com a intenção de assentar 2000 famílias na área. No entanto, o congresso vetou a operação, que se transformou em uma campanha liderada pelo principal jornal do país, ABC Color, contra o titular do INDERT e o próprio presidente da República, acusados de sobrevalorizarem o terreno com fins escusos. Tudo indica que se pretendia evitar um precedente de distribuição de terras que interessavam aos empresários da soja. Foi nesta conjuntura que se produziu a primeira ameaça séria de julgamento político de Lugo. Alderete renunciou pouco depois do impediemnto à compra culminar com um corte significativo em verbas destinadas ao INDERT pelo congresso. Foi também nesta circunstância que se criou a Liga Nacional de Carperos.

\section{ÑACUNDAY}

Em abril de 2011, cerca de 500 sem-terra ocuparam uma área em Ñacunday, na fronteira com o Brasil, desencadeando um conflito que se estenderia ao ano seguinte e repercutiria na pátria vizinha, uma vez que a área em questão foi apropriada pelo ícone do poder brasiguaio no país, Tranquilo Favero. Maior plantador de soja do Paraguai, Favero é também conhecido pelo desprezo de tonalidades racistas que expressa em relação aos trabalhadores paraguaios, contrabalanceada por uma admiração indisfarçada por Stroessner ${ }^{(6)}$. Aliás, ambos traços são comuns a muitos proprietários brasileiros no país que, em sua maioria, identificam-se politicamente com os colorados.

A ocupação foi protagonizada por um segmento de trabalhadores rurais sem-terra que radicalizou seus métodos de luta com o fracasso da aquisição da área de Teixeira. Há indícios de que o próprio governo tenha favorecido esta ação, com a intenção de realizar uma desapropriação carregada de valor simbólico que o fortalecesse politicamente tendo em vista futuras eleições, fomentando a percepção de que a reforma agrária avançava.

(6) Na entrevista que concedeu à Folha, no QG de seu grupo empresarial em Assunção, esse catarinense nascido na pequena cidade de Videira chamou os camponeses que cercam sua fazenda de delinquentes; elogiou o governo do ditador Alfredo Stroessner ("Naquela época você podia dormir com a janela aberta e ninguém te roubava. Só estamos piorando desde então"); e disse que é inútil lidar com os sem-terra na base da diplomacia, que eles têm de ser tratados "como mulher de malandro, que só obedece na base do pau" (CAPRIGLIONI, 2012). 
Nesta circunstância, o recém-constituído movimento dos "carperos" (carpas são as barracas dos acampantes), foi qualificado como oportunistas pelas organizações consideradas "históricas" do movimento camponês no país, que se opuseram aos métodos adotados.

As terras em questão têm documentação frágil e de procedência duvidosa. Porém, o argumento central dos trabalhadores rurais é que se tratam de tierras excedentes, ou seja: a superfície abarcada pela propriedade seria superior à documentação registrada em pelo menos 12 mil hectares. Diante dessa suspeita, o INDERT decidiu proceder à mensuração do terreno, mas houve resistência dos brasiguaios. Com o respaldo de uma autorização judicial e de tropas, iniciaram-se os trabalhos, mas, pouco depois, um segundo magistrado cassou o mandato original e o juiz que inicialmente o concedeu, foi punido.

Em face da intransigência encontrada, Lugo recuou. Não foi a primeira nem a última vez que reagiu assim, o que levou um analista a caracterizar sua política social como "um passo à frente e dois atrás". O caso Ñacunday provocou não somente a reação unificada do empresariado ligado à soja, mas há sinais de que o governo brasileiro também interviu:

En el período comprendido entre los meses de mayo a setiembre del 2011, el conflicto suscitado en torno al caso Ñacunday mostró no sólo la persistencia de las dificuldades enfrentadas por el gobierno con relación al tema de la Reforma Agraria, sino la emergencia del gobierno de Brasil como un actor importante en el marco del conflicto por la tierra en Paraguay. El gobierno de Brasil se interesó por el caso Ñacunday ante la inseguridad que podrían encontrarse las familias de brasiguayos. El interés del gobierno se manifestó en diversas acciones: el Cónsul adjunto del Brasil en Ciudad del Este, junto a abogados de productores y un asesor jurídico del Consulado brasileño, recorrieron la zona de Nacunday a fin de interiorizarse de la situación y el propio embajador de Brasil realizó una visita "de cortesía" al presidente del INDERT. (PROGRAMA DEMOCRATIZACIÓN Y CONSTRUCIÓN DE LA PAZ, 2012, p. 5.)

Ao final, as terras não foram recuperadas, o INDERT sofreu intervenção do governo nacional, em meio a acusações de corrupção de seu terceiro diretor (próximo aos liberais) e os camponeses se retiraram. Parte deles transladaram-se à Curuguaty, palco dos trágicos eventos que serviram de pretexto para desencadear o julgamento de Lugo.

\section{O JULGAMENTO POLÍTICO}

No campo popular, existe uma percepção consensual de que os eventos que resultaram na morte de 6 policiais e 11 camponeses no dia 15 de junho de 2012 em Curuguaty foram desencadeados por francoatiradores. Atingidos os policiais, onze camponeses dentre os poucos mais de cinquenta presentes no local foram executados ${ }^{(7)}$. A terra em questão era uma antiga reivindicação do movimento camponês, que já a ocupara e desocupara diversas vezes, apropriada por um conhecido empresário e ex-senador colorado, Blas Riquelme. O consenso em relação à ilegalidade da propriedade é tal que Frederico Franco, o presidente golpista, encampou a sua recuperação na tentativa de produzir um fato político popular - o que, diga-se de passagem, ratifica a irregularidade do desalojo que resultou na tragédia.

(7) Frederico Franco desativou a comissão montada por Lugo para investigar os acontecimentos de Curuguaty. 
Embora a deposição de Lugo tenha sido viabilizada por uma convergência de interesses variados, a articulação imediata do golpe é atribuída a dois personagens: Aldo Zucolillo e Horacio Cartes. O primeiro é um influente empresário que tem, entre outros negócios, sociedade com a Cargill no país e é dono do principal diário nacional, o ABC Color. Ainda, Zucolillo é reputado como um lobista de alto nível das multinacionais que atuam no Paraguai em geral, e do governo dos Estados Unidos em particular. Já Horacio Cartes é considerado por seus pares como um dos empresários mais bem-sucedidos do país, enquanto seus opositores descrevem-no como um dos mafiosos mais poderosos do cone sul. Seus negócios envolvem o setor financeiro, bebidas, cigarro, fazendas e até um time de futebol. Cartes pretende ser o próximo presidente do Paraguai pela Asociación Nacional Republicana, denominação oficial do Partido Colorado.

No entanto, analistas indicam que a candidatura Cartes encontrava dificuldades para transcender o âmbito do coloradismo que, por sua vez, está sujeito a permanentes disputas internas. A popularidade do presidente Lugo, que estimava-se acima de $40 \%$ apesar das limitações de seu governo, não era um óbice menor. Nesta circunstância, especula-se que Zucolillo, politicamente próximo aos colorados, teria sensibilizado Cartes sobre a urgência de uma atitude drástica para salvar seu projeto. A publicação de uma matéria no começo do ano no ABC Color em que se insinuavam vínculos de Cartes com diversos negócios ilegais, entre o contrabando de cigarros para o Brasil e o narcotráfico, pode ter contribuído para a persuasão ${ }^{(8)}$.

Consumada a chacina, a oposição subiu o tom das críticas ao presidente, acusado como responsável pelos acontecimentos por sua presumida incapacidade para lidar com os problemas do país. A reação de Lugo, por seu turno, foi defensiva. Solidarizou-se com os policiais mortos, mas não com os camponeses. E substituiu o ministro do Interior, Carlos Filizzola, por Rúben Candia Amarilla, um colorado de notórios vínculos com grupos anticomunistas do stronismo e detestado pelos movimentos sociais por sua atuação como fiscal general del Estado. De fato, uma vez empossado, o primeiro anúncio do novo ministro foi decretar o final do "protocolo" estabelecido para lidar com ocupações de terra, que previa o diálogo inicial com os manifestantes.

Ao nomear um colorado como ministro, Lugo incorreu no desprezo da esquerda ao mesmo tempo em que aprofundou o fosso que o separava dos liberais, sua base de sustentação no parlamento. A racionalidade provável por trás desta nomeação é política: Candia Amarilla seria um colorado próximo à presidenta do partido, Lilian Samaniego que, por sua vez, opõe-se internamente à candidatura de Cartes. Desgastada a relação com os liberais após quase quatro anos de convivência espúria, Lugo estaria visualizando seu futuro político em uma aproximação com setores deste partido.

No entanto, o jogo virou quando os liberais, que não precisavam de muitos motivos para assumir a máquina estatal faltando poucos meses para a eleição, acertaram-se com os colorados, que opunham-se a Lugo desde o início. O processo de impeachment concretizou-se na $24^{a}$ ocasião em que houve a ameaça de desencadeá-lo ao longo do mandato. Foi a oitava vez que um presidente paraguaio é deposto no final do seu governo.

(8) A referida matéria está disponível em: <http://www.abc.com.py/edicion-impresa/opinion/el-lado-oscuro-de-horacio-cartes-207834.html> Acesso em: 7 ago. 2012. 


\section{AINDA O GOLPE}

Uma observação superficial dos primeiros atos de Franco revela outros interesses que ansiavam por uma mudança de governo. Na semana seguinte ao golpe, foi liberada a comercialização de uma variedade de semente transgênica de algodão produzida pela Monsanto e, pouco depois, mais quatro variedades de semente de milho. Também aceleraram-se as negociações com a multinacional Rio Tinto Alcán, que pretende construir uma gigantesca planta de alumínio nas margens do Rio Paraná. Embora o Paraguai não produza bauxita, trata-se de um processo de intenso consumo energético, que pretende beneficiar-se da proximidade com a usina de Itaipu. Segundo o especialista Ricardo Canese, que assessorou o governo Lugo nas negociações com o Brasil sobre Itaipu, as condições colocadas pela multinacional canadense (segundo governo a reconhecer Franco, depois do Vaticano), implicam em um subsídio na ordem dos U\$ 14 bilhões de dólares ao longo dos próximos 20 anos - o que equivale a sete vezes o montante da dívida externa paraguaia (CANESE, 2012) ${ }^{(9)}$.

No plano das relações internacionais, divulga-se a ideia de que os Estados Unidos apoiaram o golpe, o que é coerente com o papel atribuído a Zucolillo nos acontecimentos. $\mathrm{Na}$ visão da diplomacia brasileira, a deposição de Lugo foi interpretada como um revés para a afirmação da hegemonia regional do país, e o governo movimentou-se para evitar o golpe quando este já estava engatilhado. É provável que os golpistas não esperassem o movimento seguinte - a suspensão paraguaia do Mercosul e o consequente ingresso da Venezuela no bloco. Em resposta, emissários de Franco tentam convencer colegas internacionais da justiça de sua causa, enquanto internamente denuncia-se, em tom histriônico, uma suposta reedição da Tríplice Aliança dos anos 1870 contra o país mediterrâneo. A despeito da conveniência ou não de sanções econômicas para os negócios brasileiros no país, é provável que o Itamaraty contasse com esta reação quando advogou para que não fossem aplicadas. Por outro lado, o golpe sugere um paradoxo da hegemonia regional brasileira, uma vez que o protagonismo brasiguaio no agronegócio, amparado pela diplomacia nacional, está no núcleo da questão agrária no Paraguai, principal vetor de desestabilização do governo Lugo.

Assim, embora as circunstâncias políticas ajudem a entender o modo como foi deposto Lugo, as causas da oposição intransigente que enfrentou são, evidentemente, estruturais. Os episódios envolvendo a compra de terras de Teixeira, Nacunday e Curuguaty ilustram, por um lado, a tenaz resistência das classes dominantes a qualquer mudança no padrão de relações sociais estabelecido no campo, onde o agronegócio vem expulsando aceleradamente a população camponesa, provocando o inchamento das cidades e a emigração ${ }^{(10)}$, além de agredir incessantemente aqueles que permanecem na terra, sem mencionar a devastação ambiental. Por outro lado, revelam a força do legado stronista no aparelho do Estado, assim como o seu reverso, a impotência de um governo de caráter ambíguo para avançar mudanças, ainda que mínimas, apesar do comprometimento individual de muitos militantes.

(9) Os dados manejados por Canese estão resumidos em: <http://www.tekojoja.org/tras-el-golpe-politico-el-asalto-economico-ing-ricardo-canese-subsidio-a-rio-tinto-peor-que-la-perdida-de-la-soberania-de-itaipu> Acesso em: 8 ago. 2012.

(10) Como observa Palau, o Paraguai é um caso único no mundo, em que $10 \%$ dos nacionais estão fora do país ao mesmo tempo em que $10 \%$ da população residente é constituída de estrangeiras, de origem brasileira (PALAU, 2012). 


\section{BALANÇO}

É difícil avaliar o impacto do golpe na política paraguaia. Segundo Milda Rivarola, parte da inação popular diante dos eventos deve-se ao estupor causado pela brutalidade com que se rompeu o contrato social. Deixando de lado considerações sobre a pertinência da noção de contrato social em um país em que os trabalhadores são condenados a um mundo de mínimos políticos, como diz Florestan Fernandes, o fato é que o golpe não poderia ser popular e certamente os colorados contaram com isso quando entregaram a presidência a Franco ${ }^{(11)}$. Sob esta perspectiva, Rivarola observa que o golpe pode ter um efeito politizador inesperado:

Aunque, considerando sus consecuencias mediatas, la rescisión de un contrato social paulatinamente resquebrajado en la transición y en la alternancia, está generando un efecto no querido por sus ejecutores. Nunca antes la sociedad paraguaya debatió y reflexionó como ahora sobre la política. Está hoy preguntándose en centenares de espacios, foros, organizaciones civiles o sociales qué fue, como se quebró, que será de hoy en más la democracia paraguaya. Inquiriendo qué se hizo mal, cómo quieren convivir civilizadamente los paraguayos - hombres y mujeres — después de este quiebre brutal. (RIVAROLA, 2012)

Apesar do otimismo destas linhas, prevalece no campo popular a percepção de que houve uma notável derrota. Alguns acreditam que virá um período de incontida violência, enquanto outros trabalham para que Lugo seja candidato a senador na expectativa de que puxe votos, resultando em uma composição menos desfavorável no próximo parlamento. Em uma perspectiva menos imediata Luis Aguayo, líder da reputada MNOC (Mesa Nacional de Organizaciones Campesinas) avalia, como outros, que apesar dos reveses houve um avanço em clarear o campo político, no qual a dicotomia entre liberais e colorados pode dar lugar a uma polarização entre esquerda e direita. Aguayo relata que está em curso nos movimentos camponeses uma autocrítica em relação à "trégua" adotada diante do governo Lugo, que teria resultado em um desacúmulo de força. Questionado sobre o que entendia por "desacumular forças", respondeu com clareza: não se conquistou um centímetro de terra sequer ${ }^{(12)}$.

Esta constatação sugere que é possível uma leitura oposta à de Rivarola sobre a resposta imediata ao golpe: sem ilusões quanto à fragilidade da institucionalidade vigente ${ }^{(13)}$, não houve resistência massiva porque a população sentiu que não havia muito mais a defender, em um governo que aquiesceu pacificamente inclusive à sua destituição.

Nesta perspectiva, o golpe explicita de forma caricatural, por exagerar os traços mais salientes, os limites da democracia na América Latina. No país em que a liberalização política foi conduzida pelo mesmo partido que gerenciou a ditadura, o presidente é deposto de

(11) Há um setor minoritário entre os liberais contrário ao governo Franco, liderado por um renomado militante contra a ditadura stronista, Domingo Laíno.

(12) Entrevista ao autor, 3.8.2012

(13) Segundo dados do Latinobarómetro de 2011, o parlamento e os partidos políticos são as instituições de menor credibilidade no país: $72 \%$ dos paraguaios afirmam ter pouca ou nenhuma confiança no parlamento, enquanto $74 \%$ não confiam nos partidos políticos. Dados disponíveis em: <www.latinobarometro.org >. 
forma provavelmente ilegal e seguramente ilegítima. Assim, o desenlace do governo Lugo evidencia os limites da chamada abertura democrática, em que o final quase simultâneo das ditaduras no cone sul preservou estruturas de dominação que as novas constituições foram incapazes de ameaçar, ao consagrarem direitos políticos e sociais nos marcos de Estados construídos para negá-los.

Visto pelo ângulo da democratização social, os termos em que se debatem os eventos paraguaios refletem as acanhadas balizas que referenciaram o governo Lugo, mas também indicam o estreito horizonte político prevalente na América Latina contemporânea que procura interpretá-lo: afinal, a ilegitimidade da destituição é expressão do descolamento entre o parlamento e a população que teoricamente representa. Em última análise, trata-se de um indício dramático do abismo que separa o regime político vigente dos anseios e necessidades do povo paraguaio. Em outras palavras, a ilegitimidade não se reduz ao procedimento de destituição, que remete à discussão sobre a sua legalidade, mas emana das relações sociais que endossam esta forma de fazer política, ideologicamente alcunhada de democracia.

Entrevistas realizadas em Assunção entre 31.7.2012 e 4.8.2012:

- Alberto Alderete. Ex-diretor do INDERT (Instituto Nacional de Desarrollo Rural y de la Tierra).

- Andrés Wehrle. Ex- Vice-ministro de Agricultura y Ganadería.

— Idilio Méndez Grimaldi. Jornalista e economista.

- Juan Díaz Bordenave. Membro do Consejo Nacional de Educación y Cultura.

— Luis Aguayo. Dirigente da MNOC (Mesa Nacional de las Organizaciones Campesinas)

— Luis Rojas Villagra. Coordenador BASE IS e pesquisador.

— Miguel Lovera. Ex-diretor do SENAVE (Servicio Nacional de Calidad y Sanidad Vegetal y de Semillas).

— Milda Rivarola. Engenheira agrônoma e historiadora.

— Quintín Riquelme. Sociólogo.

— Ramón Fogel. Sociólogo.

— Victor Jacinto-Flecha. Sociólogo.

\section{REFERÊNCIAS BIBLIOGRÁFICAS}

ABC Color Digital. Paraguay denuncia otra triple Alianza. Assunção, 26/6/2012. Disponível em: <http://www.abc.com.py/nacionales/denuncian-otra-triple-alianza-contra-paraguay-419073.html> Acesso em: 18 ago. 2012.

. 'Brasiguayos' pedirán a Itamaraty que respalde a Franco. Assunção, 24.6.2012. Disponível em: <http://www.abc.com.py/edicion-impresa/politica/brasiguayos-pediran-que-itamaraty--respalde-a-franco-418087.html> Acesso em: 15 ago. 2012

ALDERETE, Luciano \& NAVARRO IBARRA, Liliana. Paraguay en la encrucijada: movimiento campesino y governabilidad durante el periodo 1989-2008. Disponível em: <http://paraguay.sociales.uba.ar/ files/2011/08/P_navarro_alderete_2009.pdf> Acesso em: 18 maio 2012. 
BASE IS. Los impactos socioambientales de la soya en Paraguay. Asunción: Base IS, 2010.

CANESE, Ricardo. Entrevista ao Correio da Cidadania, 18/07/2012. Disponível em: <http://www. correiocidadania.com.br/index.php?option=com_content\&view=article\&id=7382: manchete 180 712\&catid=72:imagens-rolantes> Acesso em: 8 ago. 2012.

CAPRIGLIONI, Laura. Brasileiro faz fortuna e má fama no Paraguai. Folha de S. Paulo, 5 fev. 2012. COMISIÓN DE JUSTICIA Y VERDAD. Informe Final de la Comisión de Verdad y Justicia. Tomo IV: Tierras Mal Habidas. Asunción: Comisión de Justicia y Verdad, 2008. Disponível em: <http://www. meves.org.py> Acesso em: 20 mar. 2012.

FOGEL, Ramón; RIQUELME, Marcial. Enclave sojero: merma de soberanía y pobreza. Asunción: Ceri, 2005.

Movimientos campesinos y su orientación democrática en el Paraguay. Compilador/es: Hubert C. de Grammont (En publicación): "La construcción de la democracia en el campo latinoamericano". Buenos Aires: CLACSO, 2006.

GLAUSER, Marcos. Extranjerización del territorio paraguayo. Assunção: BASE IS, 2009.

INFORME IWGIA. El caso Ayoreo. Paraguai, sem data.

MENDEZ, Idilio. Monsanto golpea en Paraguay: Los muertos de Curuguaty y el juicio político a Lugo. Disponível em: <http://www.atilioboron.com.ar/2012/06/por-que-derrocaron-lugo.html> Acesso em: 5 ago. 2012.

MENEZES, Alfredo da Mota. A herança de Stroessner: Brasil - Paraguai, 1955-1980. São Paulo: Papirus, 1987.

MORAES, Ceres. Interesse e colaboração do Brasil e dos Estados Unidos com a ditadura de Stroessner (1954-63). Diálogos, v. 11, ns. 1 e 2, p. 55-80, 2001.

NICKSON, Andrew R. Brazilian colonization of the Eastern Border Region of Paraguay. Journal of Latin American Studies, n. 13 (maio 1981), Republicado como: Colonización brasileña de la región oriental del Paraguay. Em: FOGEL, Ramón; RIQUELME, Marcial. Enclave soyero merma de soberanía y pobreza. Assunción: CERIS, 2005. p. 219-239.

Paraguay's presidential coup: the inside story. Open Democracy, 10.7.2012. Disponível em: <http://www.opendemocracy.net/andrew-nickson/paraguays-presidential-coup-inside-story> Acesso em: 9 ago. 2012.

PALAU, Marielle (Coord.). Criminalización de la lucha campesina. Asunción: BASE IS, 2009.

PALAU, Tomas. Es logico que una sociedad agredida se defienda. Asunção: BASE IS, 2012.

et al. Los refugiados del modelo agroexportador. Impacto del monocultivo de soya en las comunidades campesinas paraguayas. Asunción: Base IS, 2007.

PROGRAMA DEMOCRATIZACIÓN Y CONSTRUCCIÓN DE LA PAZ. Monitoreo de la Política de Reforma Agraria del Gobierno Lugo. Sintesis a Diciembre 2011. Asunción, feb. 2012.

RIQUELME, Quintin. Los sin tierra en Paraguay. Conflictos agrarios y movimiento campesino. Buenos Aires: Clacso, sep. 2003.

; ROJAS, Luis; PALAU, Tomas. Acciones del Gobierno Lugo para la Reforma Agraria entre agosto de 2008 y junio de 2010. Informe final de consultoría. Assunção, dez. 2010

RIVAROLA, Milda. La rescisión del contracto social. Publicado originalmente no diário Ultima Hora, 28 jul. 2012. Disponível em: <http://ea.com.py/la-rescision-del-contrato-social/> Acesso em: 8 ago. 2012.

ROJAS, Luis. Actores del agronegocio en Paraguay. Asunción: Base IS/ Diakonia, 2009. 


\title{
EM BUSCA DE UMA IDENTIDADE LATINO-AMERICANA IN SEARCH OF A LATIN AMERICA IDENTITY
}

\author{
Fernanda Filgueiras ${ }^{(*)}$
}

\begin{abstract}
Resumo: Com as guerras de independência, a América Latina conquistou sua autonomia política; no entanto, os nacionalismos nascentes não conseguiram alcançar a independência econômica e cultural. José Martí (1853-1895), mártir da independência de Cuba, é uma das figuras mais expressivas no contexto da literatura latino-americana, do século XIX, justamente por ser um dos primeiros intelectuais a perceber a necessidade de aproximar o fragmentado bloco latino-americano. O presente trabalho se propõe a examinar de que forma se dá essa busca identitária no discurso martiano, com destaque para o ensaio Nuestra América (1891), uma vez que utiliza a literatura como ferramenta de desenvolvimento de uma nova consciência, de resistência e reafirmação das culturas locais.
\end{abstract}

Palavras-chave: Identidade. Literatura. América Latina. José Martí.

Abstract: With the Independence wars, Latin America conquered your political autonomy, however, the growing nationalisms did not to achieve the economy and cultural independence. José Martí (1853-1895), independence martyr of Cuba, is one of the expressive character in the context of Latin America literature of twenty century, mainly because he is one of the intellectuals to realize the necessity of approaching the Latin America bloc fragmented. The present research propose to examine how this identity happens into the martiano's speech, highlighting the thesis Nuestra América (1891), once that it uses the literature as an instrument to development a new conscience, of resistance and reaffirmation of local cultures.

Key-words: Identity. Literature. Latin America. José Martí.

(*) Historiadora e Mestranda no Programa de Integração da América Latina (PROLAM-USP). Pesquisadora do IAMÁ-USP. E-mail: <fernandafilgueiras@usp.br>. Este artigo é resultado parcial da pesquisa de mestrado em andamento. Recebido em 17.02.2013 e aceito em 08.05.2013. 


\section{INTRODUÇÃO}

A questão da identidade, na América Latina, de acordo com Aníbal Quijano (2005), é um projeto histórico aberto e heterogêneo, pelo fato de muitos passados estarem envolvidos nesse processo e também terem se criado novas identidades sociais como índios, negros e mestiços, por conta da expansão do colonialismo europeu.

Com isso, foram se formando o que Quijano (2005) chama de "relações intersubjetivas", ou culturais, entre dominantes e dominados, porém, marcadas pela resistência. Assim, a "latinoamericanidad" nasce em um terreno conflituoso entre o europeu e o não europeu. Nesse contexto, por um lado, desenvolveram-se novos processos identitários e, por outro, permaneceram núcleos de identidades históricas muito antigas e complexas.

É pertinente assinalar, contra todo esse pano de fundo histórico e atual, que a questão da identidade na América Latina é, mais do que nunca, um projeto histórico, aberto e heterogêneo, não só, e talvez não tanto, uma lealdade com a memória e com o passado. Porque essa história permitiu ver que na verdade são muitas memórias e muitos passados, sem ainda um caminho comum e compartilhado. (QUIJANO, 2005, p. 27)

Não podemos perder de vista que, mesmo depois de haver conquistado autonomia política, a partir das guerras pela independência, herdou-se a dependência econômica. Nesse sentido, Túlio Halperin Donghi (2005) observa que toda América Latina teve dificuldade para encontrar um equilíbrio interno, capaz de absorver as consequências das alterações que a independência trouxe consigo.

Segundo Celso Furtado (1978), as nações surgidas nas terras de colonização ibérica das Américas procuravam realçar o traço individual de cada uma, num esforço de definição das próprias personalidades nacionais e não se preocupavam pelo que existia de semelhante entre elas, apesar de terem uma história e uma língua comum. Para Furtado (1978), foram os problemas surgidos a partir da crise de 1929 que abriram o caminho à formação da atual consciência latino-americana, por conta das dificuldades de abastecimento de produtos tradicionalmente importados.

Entendemos que a identidade, enquanto processo histórico-social, envolve o sentimento de pertencimento a um determinado grupo, em um processo resultante da experiência coletiva, em que está presente também a diferenciação do outro. Desse modo, a identidade não é um processo natural, ou seja, ela se concretiza na prática das relações sociais e necessita de elementos que aproximará as pessoas formando grupos identitários, e ao mesmo tempo os diferenciando de outros.

Portanto, é necessária uma consciência social, atrelada a um conjunto de traços culturais que, fortalecidos nas suas práticas cotidianas, configurarão tal identidade. Assim, "do ponto de vista da disciplina histórica, importa assinalar que as identidades não são aqui entendidas como essências ou entidades imutáveis, mas como processos incessantes de construção/reconstrução dos imaginários sociais" (BEIRED; BARBOSA, 2010, p. 8).

Nessa perspectiva, muitos literatos da América Latina preocuparam-se com a configuração identitária e histórica do "novo mundo" partindo, por um lado, de uma visão 
mais política e principalmente de compromisso social e, por outro, do pensamento mítico e simbólico inerente à América (PEREIRA, 2007). Com a formação das nações independentes e com o fim dos impérios português e espanhol na América Latina, a circulação de escritores, intelectuais e artistas entre os novos países se desenvolveu especialmente na América de língua espanhola. Cresceu também a presença de intelectuais e artistas, e aí inclusive brasileiros, na Europa, especialmente em Paris (AGUIAR, 2006). Neste ponto:

[...] vários escritores mesclaram, produtivamente, discurso histórico e poético em suas obras, aceitando a difícil missão de "reescrever" a história segundo uma visão mais próxima, isto é, de dentro das veias de seu próprio continente, em oposição àquela visão etnocêntrica e eurocêntrica a partir da qual o Novo Mundo foi "criado" nos séculos XV e XVI. (PEREIRA, 2007, p. 7)

Logo, a América Latina busca deixar de ser o "projeto da consciência alheia" para se tornar, ainda que com toda a dificuldade, um "projeto da consciência própria dos latino-americanos" (PEREIRA, 2007, p. 23). De qualquer maneira, a literatura teve um papel efetivo na constituição de uma consciência nacional e, assim, na construção das próprias nações latino-americanas, uma vez que muitos escritores estiveram engajados nas questões sociais e políticas.

José Martí (1853-1895), mártir da independência de Cuba, é umas das figuras mais expressivas no contexto da literatura latino-americana do século XIX, justamente por ser um dos primeiros intelectuais a perceber a necessidade de aproximar o fragmentado bloco latino-americano. O presente trabalho se propõe a examinar de que forma se dá essa busca identitária no discurso martiano, com destaque para o ensaio Nuestra América (1891), uma vez que utiliza a literatura como ferramenta de desenvolvimento de uma nova consciência, de resistência e reafirmação das culturas locais.

\section{NOSSA AMÉRICA}

O pensamento de José Martí não pode ser visto separadamente de sua militância política. O objetivo de promover a independência de Cuba e, por meio dela, deter o avanço do imperialismo norte-americano é o que vai delinear, definitivamente, a dimensão de seu pensamento de uma maneira mais ampla. $\mathrm{O}$ ápice desse pensamento é expresso no ensaio Nuestra América publicado na Revista Ilustrada de Nova York em 10 de janeiro de 1891 e no jornal mexicano El Partido Liberal, em 30 de janeiro do mesmo ano. A busca identitária nessa obra se pauta em dois pontos chaves: consciência e autoctonia. Martí percebe que só se construiria uma nova América a partir de uma tomada de consciência da condição social do continente. Essa consciência seria a arma adequada e eficaz para promover, inicialmente, a independência de Cuba e a partir dela uma segunda independência da América Latina.

Para tanto, seria necessário criar uma cultura própria que atendesse aos próprios problemas e, não mais, importar "soluções" externas, ou seja, pensar em um modo de vida alternativo, embasado em uma consciência anticolonial, fomentando a valorização das culturas locais perante o desprezo do olhar estrangeiro. Desse modo, reescrever a 
própria história ante a memória oficial possibilitaria, na visão de Martí, uma integração, não no sentido de federalismo do continente e sim da "alma continental" que resultaria na superação dos problemas herdados dos séculos de exploração colonial.

\section{3. "TRINCHEIRAS DE IDEIAS": POR UMA CONSCIÊNCIA PRÓPRIA}

No ensaio Nuestra América, Martí deixa clara a necessidade de iniciar um processo de integração da América Latina. No entanto, para que houvesse essa unidade, era preciso utilizar as armas adequadas, isto é, "las armas del juicio". Tais armas, na visão de Martí, seriam capazes de vencer as demais, uma vez que formariam "trincheras de ideas" mais eficazes a "trincheras de piedra".

No entanto, como construir um conhecimento capaz de erguer uma trincheira de ideias? Martí entendia que tais armas seriam adquiridas por meio de uma tomada de consciência da realidade em que se vivia. Essa consciência seria construída e amadurecida, pelo conhecimento obtido a partir de nossa realidade concreta e de nosso posicionamento engajado na causa de defesa da "mãe América". Por sua vez, resultaria em um sentimento de pertencimento, isto é, uma identidade sociocultural. E essa identificação seria o elo que integraria nosso fragmentado continente e consequentemente daria condições de promover o desenvolvimento interno e fortalecer nossa independência, diante dos perigos externos.

Desse modo, seria importante recorrermos às nossas memórias, pois estas seriam nossas referências para, no presente, reverter os males provocados pelo passado colonial e reconstruir nossa história a fim de não perpetuarmos tais problemas. "La historia de América, de los incas acá, ha de enseñarse al dedillo, aunque no se enseñe la de los arcontes de Grecia. Nuestra Grecia es preferible a la Grecia que no es nuestra. Nos es más necesaria”, destacava com convicção.

Talvez soe como utópicas essas proposições martianas, mas o fato é que contribuem para levantar esperanças, aliadas a ações práticas, para reverter tal quadro enfrentado até então e, a partir daí, construir um novo futuro. Portanto, nossas memórias seriam a bússola, ou seja, o ponto de referência para nos reconhecermos e projetarmos nosso futuro ainda em nosso presente. "Resolver el problema después de conocer sus elementos, es más fácil que resolver el problema sin conocerlos. [...] Conocer es resolver" (MARTí, 1891). E esse conhecimento crítico se tornaria a arma eficaz para pensarmos por nós mesmos, e, dessa forma "No hay proa que taje una nube de ideas. Una idea enérgica, flameada a tiempo ante el mundo, para, como la bandera mística del juicio final, a un escuadrón de acorazados" (MARTí, 1891).

Logo, a materialização de uma identidade latino-americana, para Martí, se tratava de um processo longo que não necessariamente implicasse na união entre os Estados. Assim, evitava o ideal bolivariano que desconhecia, naquele momento, as singularidades locais, uma vez que, "El problema de la independencia no era el cambio deformas, sino el cambio de espíritu" (MARTí, 1891).

Por isso, logo no início do Ensaio, Martí alerta para a importância de que "Estos tiempos no son para acostarse con el pañuelo en la cabeza, sino con las armas en la almohada [...]" (MARTí, 1891). Temia, justamente, que, se não fizéssemos uso das "armas del 
juicio" certamente outros a usariam contra nós. Era urgente uma tomada de consciência coletiva ante essa problemática com o objetivo de superá-la. "Es la hora del recuento, y de la marcha unida, y hemos de andar en cuadro apretado, como la plata en las raíces de los Andes" (MARTÍ, 1891). Assim, acreditava que para se alcançar autonomia econômica, e cultural, era preciso integrar a fragmentada América Latina, pois só dessa forma seria possível romper os vínculos de dominação e dependência com os países de alto desenvolvimento industrial capitalista.

Para tanto, Martí utiliza suas narrativas, literárias e jornalísticas, como ferramenta de desenvolvimento dessa nova consciência, de resistência e reafirmação das culturas locais. É importante salientarmos que Martí ${ }^{(1)}$ nasce em um contexto de insatisfação e luta pela independência de $\mathrm{Cuba}^{(2)}$. Nesse contexto, a ilha ${ }^{(3)}$ era a única colônia espanhola que não havia, até então, alcançado sua independência. Logo, é envolvido, desde criança, pelas ideias independentistas que se propagavam pelas ruas, na medida em que "a ideia de separar Cuba da Espanha ia se desenvolvendo, com suas irreconciliáveis diferenças e com seus grandes mortos ao mediar o século XIX" (RETAMAR, 1983, p. 14).

Em nossa visão, suas narrativas não se trata de uma utopia ou um idealismo vazio, e sim um pensamento pautado na realidade, pois apresenta propostas concretas de afirmação e consolidação da dignidade dos latino-americanos. Entretanto, é preciso compreender que seu conceito de identidade é definido como um processo de projeção para o futuro, anticolonial, libertador e de amplitude continental.

Portanto, era indispensável descolonizar a consciência para se atingir o reconhecimento de si e a diferenciação do outro. Esta seria a prerrogativa fundamental para que seu projeto de transformação social e reafirmação cultural pudesse se concretizar. Martí recomendava que nossa América criasse uma nova imagem de si mesma e não mais, simplesmente, introjetasse ideias alheias sem nenhum esforço crítico.

Seu pensamento, em nosso entender, não deve ser considerado como essencialista uma vez que não focava apenas nos aspectos autóctones. Mais que isso, considerava importante assimilar o que houvesse de melhor nas demais culturas, quer seja da Europa ou dos Estados Unidos. Assim, a autoctonia defendida por Martí não era fechada em si mesma, mas

(1) José Julián Martí Pérez nasceu em 28 de janeiro de 1853, filho de espanhóis imigrantes pobres da região de Valência e das Ilhas Canárias.

(2) Segundo Fernando Martínez Heredia (2006): "Cuba é o país mais ocidental da região do Caribe. A área do arquipélago cubano é aproximadamente a soma da extensão de todo o resto do Caribe insular; ocupa uma posição singular diante das Américas, com respeito às comunidades continentais, entre o golfo do México e o mar do Caribe. Domina os estreitos da área e é contígua aos EUA e ao Atlântico norte. Essa situação geográfica tão estratégica sempre foi uma influência notável em sua história." (2006, p. 342) Habitada há pelo menos 10 mil anos e, quando Cristóvão Colombo atracou na ilha em sua primeira viagem, em 28 de outubro de 1492, lá existia uma população estimada em não menos de 200 mil habitantes, em estágios variados, desde conhecedores da agricultura e da cerâmica até coletores.

(3) De acordo com Heredia (2006), Cuba foi ocupada e colonizada pelos espanhóis, a partir de 1510, servindo de ponto de partida para as expedições que dominaram o atual México e outras regiões entre a Flórida e o norte da América do Sul. Na ilha, foram fundadas vilas e constituído um governo geral e em relações de exploração e opressão foi estabelecida a economia conhecida como encomienda que tinha como objetivo a busca por ouro e meios de subsistência. Os serviços forçados somados às doenças trazidas pelos europeus dizimaram a população nativa e "[...] em um período não muito extenso, o que restou dessa população praticamente desapareceu absorvido pela mestiçagem" (HEREDIA, 2006, p. 342). Região preferida pela Espanha graças à sua localização estratégica, Cuba "[...] tornou-se uma das colônias mais modernas e 'ricas' do mundo, primeira exportadora mundial de açúcar de cana, muito bem integrada ao capitalismo mundial e na ponta de novas tecnologias" (HEREDIA, 2006, 343). 
relacionava-se com aspectos estrangeiros que pudessem ser assimilados e ressignificados em algo próprio e que trouxesse benefício para nossa América. Trata-se de uma visão de mundo ampliada e que considera todas as possibilidades para valorizar o continente.

Ele mesmo assimilou diversos elementos em sua trajetória teórica e bebeu de diversas fontes, incluindo europeias e estadunidenses, que lhe proporcionaram ter uma erudição grandiosa. Desse modo, por sua própria experiência, não via vantagens na ignorância, no entanto, defendia que os povos de nossa América fossem letrados no sentido mais amplo, e que uma massa de iletrados não seria capaz de fazer frente ao imperialismo norte-americano.

Observava, também, a necessidade de investigar nossas raízes para reescrevermos nossa história livre de qualquer pensamento de inferioridade e do desdém do olhar estrangeiro que desconhecia nossas próprias origens e riquezas e, assim, desconsideravam nossas potencialidades enquanto repúblicas "recém-nascidas". Conhecermos e nos reconhecermos, na visão de Martí, era preciso para nos fortalecer e garantir nossa independência não apenas na esfera política, mas também cultural e econômica. Era preciso valorizar nossas memórias e não nos envergonhar de nossa "Mãe América". Contudo, para se alcançar um desenvolvimento autônomo, eram indispensáveis propostas práticas a fim de vencer "El tigre de adentro se echa por al hendija, y el tigre de afuera" (MARTÍ, 1891).

\section{EM DEFESA DO FAZER LOCAL}

A partir de sua vivência nos Estados Unidos, Martí percebe que "o outro" da América Latina deixa de ser a Europa e passa a ser "o gigante do Norte". Martí entendía que "El desdén del vecino formidable que no la conoce es el peligro mayor de nuestra América". De tal modo Martí se torna um anti-imperialista, ao compreender, então, o risco que nossa América corria com o "monstro" imperialista que avançava pela América Latina. "Em fins da década de oitenta, o que até então parecia apenas receio de Martí e de uns poucos, quanto aos turvos desígnios norte-americanos em relação à outra América, começa a se tornar realidade visível para todos" (RETAMAR, 1983, p. 21). É neste ponto que:

Nos Estados Unidos, país estrangeiro onde permanece mais tempo, familiariza-se com a "América europeia" como a chamará e, a princípio, sem deixar de reconhecer suas virtudes, logo vê, espantado, que reaparecem nela os vícios que acreditava ter deixado para trás, na Europa (que eram as mazelas do capitalismo desenvolvido) e verifica, assim, a diferença de estrutura e espírito entre as duas Américas. Além do que, e isto é talvez o mais importante, Martí mora nos Estados Unidos justamente no momento em que a nação passa de seu capitalismo pré-monopolista para o capitalismo monopolista e imperialista que a levará, inexoravelmente, a se abalançar sobre o mundo: primeiro sobre a América Latina e o Caribe, e em particular sobre Cuba. (RETAMAR, 1983, p. 18)

A partir daí, sua busca por uma identidade latino-americana ganha força a fim de impedir mais um movimento colonial de imposição e exploração do continente, agora por parte dos Estados Unidos da América. Defender as "trincheiras de ideias" seria uma estratégia para vencer a ideologia da "outra Europa" de pôr em prática a ideologia do 
pan-americanismo, que era a integração da América Latina sob sua liderança. Martí tinha consciência de que:

Pero otro peligro corre, acaso, nuestra América, que no le viene de sí, sino de la diferencia de orígenes, métodos e intereses entre los dos factores continentales, y es la hora próxima en que se le acerque, demandando relaciones íntimas, un pueblo emprendedor y pujante que la desconoce y la desdeña. (MARTÍ, 1891)

A economia norte-americana teve um crescimento industrial favorecido pela política protecionista. No entanto, essa mesma política que teria fortalecido o mercado interno elevava os preços das matérias-primas importadas encarecendo seus produtos, resultando nas dificuldades no mercado externo por conta da concorrência europeia. A América Latina seria a solução em termos de mercado consumidor e como fornecedora de matéria-prima a um baixo custo.

Os longos anos de vivência nesse país possibilitaram a Martí entender o objetivo do imperialismo norte-americano de impedir o desenvolvimento de maneira livre e contínua de nossas riquezas limitando nossa capacidade criadora. Dessa vez, o perigo da política imperialista norte-americana se daria de forma sutil e não de forma direta como no colonialismo espanhol. Não mais apenas um domínio territorial, e sim, submeter nossa América tanto no campo econômico, quanto no cultural, ao seu domínio. Daí seu alerta a respeito do desprezo da "outra" América:

El desdén del vecino formidable, que no la conoce, es el peligro mayor de nuestra América; y urge, porque el día de la visita está próximo, que el vecino la conozca, la conozca pronto, para que no la desdeñe. Por el respeto, luego que la conociese, sacaría de ella las manos. (MARTí, 1891)

Por isso, era importante ter esse conhecimento para lutar contra o neocolonialismo: "Es la hora del recuento, y de la marcha unida, y hemos de andar en cuadro apretado", dizia Martí. É importante ressaltar que não pregou o ódio ao povo norte-americano. Ele respeitava muitas personalidades do país, e não via nenhum problema estudar aspectos que considerasse positivos para serem aproveitados adequadamente na América Latina. Em verdade, seu desejo criador, anticolonial, tinha como pano de fundo a valorização das culturas locais.

Temia que as potências estrangeiras se aproveitassem da divisão e da debilidade interna, daí apontava que "Los pueblos que no se conocen han de darse prisa para conocerse, como quienes van a pelear juntos", por observar que um grande problema estava presente, uma vez que a nacionalidade das recentes repúblicas não representava o autóctone o negro escravizado e o mestiço. Todos esses grupos eram a maioria da população, contudo, a minoria branca, de origem europeia, não pretendia inserir essas populações no projeto nacional.

Isso, também, se deve ao fato de que suas culturas eram desprezadas e inferiorizadas e nenhuma política pública tinha sido, até então, criada com a finalidade de inserir essas pessoas na nova sociedade que se formava. Por isso, apontava como uma das soluções concretas para o continente incentivar o conhecimento dos diversos povos que o compunham a fim de, definitivamente, transformar o sistema opressor que preparava as pessoas apenas 
para conviverem dentro de uma estrutura de dominação e dependência. Para tanto, era preciso se ver, se reconhecer e estar engajado nessa causa para não mais se enfrentar "[...] como hermanos celosos, que quieren los dos la misma tierra, o el de casa chica, que le tiene envidia al de casa mejor, [...]" (MARTÍ, 1891).

Além disso, Martí chamava a atenção para o fato de que, mesmo após a independência, a "alma continental" permanecia com ares coloniais. "La colonia continuó viviendo en la república [...]" (MARTÍ, 1891). Considerava que houve uma independência política, mas o "espírito" continuava aprisionado; dessa forma, era necessário superar o espírito colonial ainda existente nas novas repúblicas independentes para se alcançar a independência cultural. Reconhecia que "[...] se imita demasiado, y que la salvación está en crear. Crear es la palabra de pase de esta generación" (MARTÍ, 1891). Para ele, era preciso criar uma nova cultura, apropriada à realidade de nossa América, a fim de que pudéssemos alcançar desenvolvimento em todas as esferas sociais.

Havia em Martí certa urgência, visto que uma elite e um governo de mentalidade colonial, mais preocupado em copiar costumes e modelos estrangeiros enquanto que no interior do continente as injustiças sociais submetiam a maioria da população local. Desse modo, nossa América estaria vulnerável aos tentáculos do monstro do norte. Assim, tornava-se urgente desenvolver e defender nossa América, mas era preciso que todos se sentissem pertencente a ela. Isso só seria possível com condições dignas de sobrevivência.

Via, na importação de modelos estrangeiros, o maior problema interno de nossa América e esse entrave se encontrava na insistência de os governantes utilizarem leis importadas de realidades distintas da nossa. Era necessário uma autoavaliação das reais necessidades do continente e a partir desse diagnóstico elaborar um modelo político adequado à essa realidade específica.

A lo que es, allí donde se gobierna, hay que atender para gobernar bien; y el buen gobernante en América no es el que sabe cómo se gobierna el alemán o el francés, sino el que sabe con qué elementos está hecho su país, y cómo puede ir guiándolos en junto, para llegar, por métodos e instituciones nacidas del país mismo, a aquel estado apetecible donde cada hombre se conoce y ejerce, y disfrutan todos de la abundancia que la Naturaleza puso para todos en el pueblo que fecundan con su trabajo y defienden con sus vidas. El gobierno ha de nacer del país. El espíritu del gobierno ha de ser el del país. La forma de gobierno ha de avenirse a la constitución propia del país. El gobierno no es más que el equilibrio de los elementos naturales del país. (MARTÍ, 1891)

Enxergava nisso tudo um problema ainda maior: a América Latina como um todo corria sérios perigos ao negar suas origens, uma vez que perdendo-se a memória perde-se junto a identidade e, dessa maneira, fica-se vulnerável aos ataques do "monstro do norte". Portanto, quanto maior fosse a identificação continental maior seria a integração e menor a dependência. Sendo assim:

[...] el deber urgente de nuestra América es enseñarse como es, una en alma e intento, vencedora veloz de un pasado sofocante, manchada sólo con sangre de abono que arranca a las manos la pelea con las ruinas, y la de las venas que nos dejaron picadas nuestros dueños. (MARTÍ, 1891) 
Indica algumas das situações socioeconômicas e entende que o problema não é a incapacidade dos latino-americanos e sim a uma política dirigida por uma classe autocrática oligárquica que governava em seu próprio benefício deixando de lado o restante da população.

La incapacidad no está en el país naciente, que pide formas que se le acomoden y grandeza útil, sino en los que quieren regir pueblos originales, de composición singular y violenta, con leyes heredadas de cuatro siglos de práctica libre en los Estados Unidos, de diecinueve siglos de monarquía en Francia. (MARTí, 1891)

Para Martí, as transformações socioeconômicas teriam de se dar em dois eixos principais: a superação do atraso econômico e a eliminação das desigualdades sociais. Por isso, criticava o funcionamento da política liberal na América Latina, pois com esse sistema político seria difícil extinguir com os traços coloniais deixados em nossa sociedade, o que consequentemente criaria novas formas de dominação. O liberalismo era um modelo econômico que contribuía para manter as condições de desigualdade social, porque contribuía para criar e manter relações econômicas que beneficiariam países estrangeiros.

Defendia, também, um novo sistema educacional que deveria iniciar na escola primária e seguir até a universidade, no sentido de construir um saber crítico, no qual, "Los pueblos han de vivir criticándose, porque la crítica es la salud; pero con un solo pecho y una sola mente" (MARTí, 1891). O importante, na visão de Martí, era criar, ser original ainda que essa originalidade contivesse elementos estrangeiros. Esse não seria o problema, desde que assimilados, de forma crítica, e adaptados de acordo a realidade local. O que não deveria acontecer era uma cópia desses elementos sem nenhuma criticidade. Em verdade nossa criatividade deveria superar a imitação.

Em sua percepção, era preciso criar leis próprias que estivessem de acordo com a especificidade do continente para organizar os novos Estados, considerando suas características culturais. Para ele o governo deveria organizar a sociedade a partir de seus elementos próprios e não mais por modelos importados. "[...] el lujo venenoso, enemigo de la libertad, pudre al hombre liviano y abre la puerta al extranjero" (MARTí, 1891), ou seja, teríamos de buscar estratégias próprias de desenvolvimento local. Para isso, era imprescindível ao governante conhecer o seu país para governá-lo bem, onde todos pudessem gozar de liberdade. "Conocer el país, y gobernarlo conforme al conocimiento es el único modo de librarlo de tiranías". Tal liberdade deveria ser primeiramente alcançada pela libertação das ideias e consequentemente "[...] la libertad, para ser viable, tiene que ser sincera y plena; que si la república no abre los brazos a todos y adelanta con todos, muere la república" (MARTí, 1891).

Portanto, insiste em uma busca identitária que envolvia o desafio de nos conhecermos, para entendermos nossa realidade e, a partir daí, discernirmos os problemas e visualizar soluções adequadas. Por isso, aponta para a fragmentação e consequentemente a ausência de identidade: "Éramos una visión, con el pecho de atleta, las manos de petimetre y la frente de niño. Éramos una máscara, con los calzones de Inglaterra, el chaleco parisiense, el chaquetón de Norteamérica y la montera de España" (MARTí, 1891). 


\section{CONSIDERAÇÕES FINAIS}

A América Latina vem de um longo processo histórico marcado pela exploração colonial, governos autoritários e recorrente corrupção, além da dependência externa. No entanto, a solução dos problemas de um grupo social, em nível nacional ou continental, não se reduz apenas aos aspectos econômicos ou políticos. Pelas relações culturais, as pessoas se definem pertencentes ou não a um grupo. Assim, a literatura pode ser uma ferramenta de comunicação e de desenvolvimento de uma identidade de um povo que compartilha a mesma memória histórica.

José Martí por meio de suas experiências, empíricas e teóricas, desenvolve uma consciência social compromissada politicamente não apenas em relação ao seu país de origem, Cuba, mas também ampliando essa percepção com o objetivo de construir uma unidade continental, a fim de fortalecer Nossa América ante os perigos externos. Nesse sentido, pretendia "fundar" uma nova América Latina enfrentando o atraso socioeconômico provocado por três séculos de colonização.

Ao seu modo, contribuiu no que diz respeito a um fazer próprio, com nova vertente autóctone, não copiativa partindo, por um lado, de uma visão mais política e principalmente de compromisso social, ou seja, não mais para agradar europeus, como também não mais colonizada, mas orgulhosa do seu fazer local. Nessa perspectiva, saber quem somos, reconhecendo nossos traços comuns sem ignorarmos as singularidades, considerando que identidade, resistência e dependência cultural, são termos inter-relacionados. Desse modo, Martí sabia que quanto maior fosse a integração latino-americana, menor seria a dependência, quer seja cultural ou econômica.

\section{REFERÊNCIAS BIBLIOGRÁFICAS}

AGUIAR, Flavio Wolf de. Literatura. In: SADER, Emir et al. Latinoamericana: Enciclopédia contemporânea da América Latina e do Caribe. São Paulo: Boitempo, 2006.

BEIRED, José Luis Bendicho; BARBOSA, Carlos Alberto Sampaio (Orgs.). Política e identidade cultural na América Latina. São Paulo: Cultura Acadêmica, 2010.

DONGHI, Túlio Halperin. A História da América Latina. São Paulo: Paz e Terra, 2005.

FURTADO, Celso. A Economia Latino-Americana. São Paulo: Companhia das Letras, 1978.

HEREDIA, Fernando Martínez. Cuba. In: SADER, Emir et al. Latinoamericana: Enciclopédia contemporânea da América Latina e do Caribe. São Paulo: Boitempo, 2006.

MARTÍ, José. Nuestra América. Nova York, 1891. Disponível em: <http://www.analitica.com/bitblio/ jmarti/nuestra_america.asp> Acesso em: 02 fev. 2013.

PEREIRA, Diana Araujo. A palavra poética: magia e revolução na cartografia latino-americana. Tese doutoral apresentada à Comissão de Pós-Graduação da Faculdade de Letras da Universidade Federal do Rio de Janeiro, 2007.

QUIJANO, Aníbal. Dom Quixote e os moinhos de vento na América Latina. Dossiê América Latina. In: Revista Estudos Avançados do Instituto de Estudos Avançados (IEA) da USP, São Paulo, vol. 19, n. 55, pp. 9-31, dez. 2005. Disponível em: <http://www.scielo.br/scielo.php?script=sci_arttext\&p id=S0103-40142005000300002> Acesso em: 20 abr. 2013.

RETAMAR, Roberto Fernández. Introdução a José Martí. In: Nossa América — Antologia. Trad. Maria Angélica de Almeida Trajber. São Paulo: Hucitec, 1983. 